\title{
Research on the Train-Bridge Coupled Vibration and Dynamic Performance of Steel Box Hybrid Girder Cable-Stayed Railway Bridge
}

\author{
Yadong YAO, Baishun XU, Yan WANG
}

\begin{abstract}
Based on the Yongjiang Bridge, this paper used the numerical calculation and the field dynamic load test to study the coupled vibration and dynamic response of the steel box hybrid girder cable-stayed railway bridge. Each vehicle in the train was simulated with 31 degrees of freedom, and the oscillatory differential equation of vehiclebridge coupling was established by MATLAB software. Afterwards, the field tests were also conducted to determine the free vibration characteristics as well as the strain, displacement, and acceleration of the bridge superstructure under trains moving at different speeds and braking at a specified position from a set speed. According to the dynamic load test and Vehicle-Bridge Coupling Vibration analysis, the following conclusions are obtained: (1) The calculated results of vehicle-bridge coupling vibration agreed well with the measured ones, and the program could be used to analyze the dynamic performance of Railway cable-stayed bridges with steel box composite girders. (2) The measured first-order natural frequencies of transverse, vertical and longitudinal vibration were $0,39 \mathrm{~Hz} ; 0,49 \mathrm{~Hz}$ and $0,88 \mathrm{~Hz}$, respectively. The dynamic coefficients are $1,04-1,13$, the maximum lateral and vertical accelerations are $1,10 \mathrm{~m} / \mathrm{s}^{2}$ and $1,11 \mathrm{~m} / \mathrm{s}^{2}$, and the maximum derailment coefficient and load reduction rate are 0,55 and 0,39 , respectively. These data showed that the dynamic parameters of bridges and vehicles met the requirements and had good stiffness and dynamic performance. (3) This paper, using the frequency limit of simply supported beam to restrain the natural frequencies of cable-stayed bridges is not appropriate, and it is necessary to propose the natural frequency limit value of cable-stayed bridge.
\end{abstract}

Keywords: coupled vibration; dynamic load test; dynamic parameters; hybrid girder; natural frequency

\section{INTRODUCTION}

With the maturity of technology and the rapid development of economy, the railway is going towards heavy-duty and high-speed, and the problem of coupled vibration of vehicles and bridges has become increasingly prominent [1]. Due to the inherent irregularity of the track, the serpentine motion of the wheel and the load of wheel, the bridge will vibrate when the train goes over the bridge. The vibration will lead to an increase in the deformation and internal force of the bridge effecting the normal use of bridges, even lead to fatigue-damaged and life reduction of the bridge. In turn, the vibration of the bridge structure generates a power shock of the moving train, causing the cargo damage and affecting the safety and stability of the vehicle.

As early as 1976, Fryba [2] began the study of random vibration of bridge under a moving load. Since 1990s, many researchers have begun to investigate the theory of vehicle-bridge coupling calculation and computer simulation [3-10]. At the same time, the study of bridge model has developed from simple, small and medium span to complex and long span. The calculation of train-bridge coupled vibration is very complex, which involves many structures in the train system and bridge system. Therefore, a relatively accurate and easy to be popularized method for vehicle-bridge coupled dynamic calculation is urgently needed. In 2005, Shan et al. [3] adopted the vehicle-bridge coupling theory to establish the dynamic model and motion equation of the vehicle and X-style arch bridge. X-style arch bridge is a through tied arch bridge with arches tilted inward and connected by beams and shaped like a basket handle. The dynamic performance of the bridge was evaluated by transverse and vertical displacement, dynamic amplification coefficient, derailment coefficient and wheel load reduction rate. In 2009, M. Gladys et al. [4] presented the spectral analysis of the beam's vibration with uncertain parameters under a random train of moving forces which forms a filtered Poisson process. In the same year, Wei et al. [5] studied the dynamic performance of continuous rigid frame bridge by using the bridge dynamic analysis program BDAP and the results of Fujiang Bridge dynamic test. In 2011, Cui et al. [6] used the combined simulation method of multi-system dynamics software SIMPACK and ANSYS to calculate the dynamic performance of double-tower steel truss cable-stayed bridge under train action. In 2012, Zhai et al. [7] studied the effect of bridge stiffness on vehicle-rail-bridge coupling dynamic performance based on the theory of vehicle-rail-bridge dynamic interaction by taking highspeed railway simply supported box girder bridge and double-block ballastless track as the research object. In the same year, Zeng et al. [8] studied the lateral stability of bridges under different train speeds by using the energy increment analysis method of system motion stability. In 2015 , Rocha et al. assessed the running safety of highspeed trains on a short-span bridge. A probabilistic approach that combines Monte Carlo simulation with the extreme value theory is used and the existence of track irregularities is taken into account along with the variability of parameters related to the bridge, the track and the train [9]. In 2017, Gou et al. [10] explored the characteristics of coupled train-bridge vibration and dynamic performance of a T-shaped rigid frame bridge with the background of Ma Shuihe Bridge in YichangWanzhou railway line.

In summary, the research on dynamic performance of bridges is mainly concentrated on continuous rigid frame bridges, arch bridges, suspension bridges, cable-stayed bridges and other bridge types [11-28]. But the research on hybrid girder cable-stayed bridge of railway is relatively scarce. Moreover, most of the researches only rely on Vehicle-bridge Coupled Vibration theory, and lack of comprehensive evaluation of bridge structure combined with real bridge dynamic load test. Therefore, it is necessary to adopt these two methods for detailed study. The purpose is to update the bridge structure model and provide a basis for the design of new bridges.

In this paper, the dynamic performance of railway steel box hybrid girder cable-stayed railway bridge is studied by combining vehicle-bridge coupled vibration theory with the field dynamic load test. Through them, the dynamic 
indices of the vehicle, stability of the train and the running safety are calculated by the vehicle-bridge coupled vibration theory. The actual modal parameters and vibration response of the bridge structure are obtained accurately from the field dynamic load test, the actual working state of the bridge under different train running speed is tested, and the dynamic deflection, dynamic strain, lateral and vertical amplitude and acceleration of the bridge span structure under the moving load. Finally, it is analyzed and evaluated whether the dynamic coefficients and the longitudinal and transverse stiffness of the bridge meet the specification requirements. The research in this paper can accumulate relevant information for the operation management and maintenance of this type of railway bridge, and also provide relevant basis for these structural designs.

\section{BRIDGE CHARACTERISTICS}

Yongjiang Bridge is the largest span steel box mixed girdercable-stayed bridge in Asia. The bridge is a semifloating structure system with double towers and double cable surfaces. Vertical restraint and longitudinal movement are set at $\mathrm{P} 1 \sim \mathrm{P} 4$ pier and $\mathrm{P} 7 \sim \mathrm{P} 10$ pier; vertical and horizontal constraints are set at the P5 and P6 tower, and damping limiters are set longitudinally. The span combination of the bridge is $(53+50+50+66+468+66$ $+66+50+50+53) \mathrm{m}$, see Fig. 1. The 400,9 m beam section in the main span is composed of a single box fivecompartment steel box girder with wind fairing. The length of stiffness transition section is $5,0 \mathrm{~m}$ and the steel-concrete combination section is $7,35 \mathrm{~m}$. The rest beam sections are all prestressed concrete box girders with single box and three chambers. The height of each section is $5 \mathrm{~m}$, and the outer contour of the steel box girder is the same as that of the concrete box girder. The bridge deck adopts ballasted seamless track, wheel-rail adopts P60 steel rail, sleeper adopts new type III concrete sleeper, and the thickness of ballast at the bottom of sleeper is $35 \mathrm{~cm}$, see Fig. 2 .

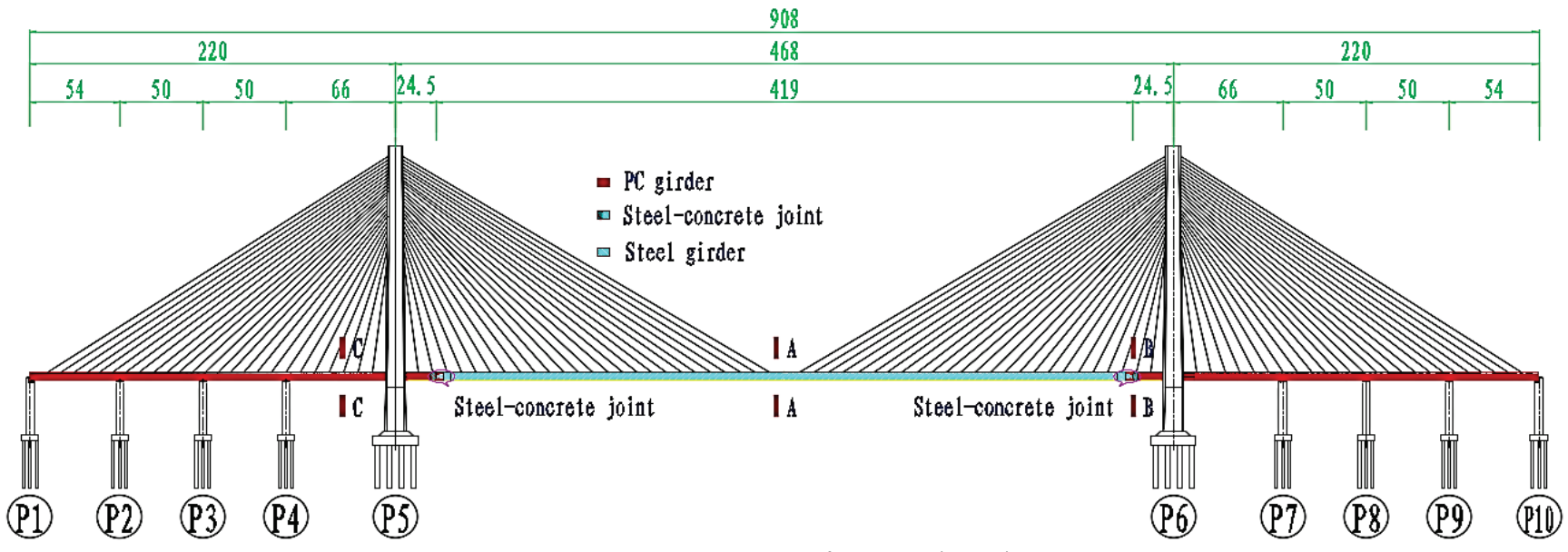

Figure 1 Elevation view of the Bridge (unit: $\mathrm{m}$ )

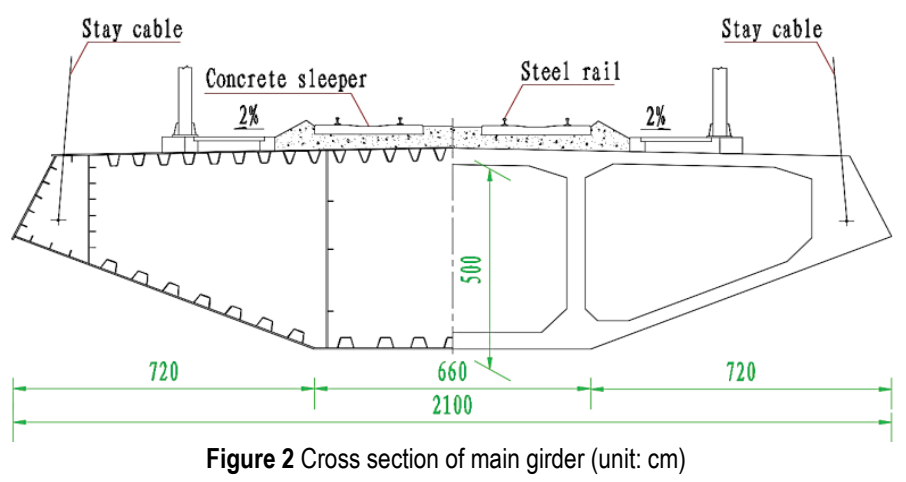

\section{VEHICLE-BRIDGE COUPLED VIBRATION ANALYSIS MODEL}

The vehicle-bridge coupled vibration model consists of vehicle mode and the bridge model, and the relationship between them is established through certain wheel-rail movement. The wheel-rail movement adopts German low interference track irregularity data [29]. The bridge model is established by multi-degree-of-freedom finite element model and the vehicle model is established by rigid body dynamics.

\subsection{Bridge Model}

When establishing the bridge finite element model, it is necessary to accurately simulate the connections between the components and the boundary conditions of the structure. Based on the following assumptions, the vibration responses of bridges and vehicles are studied by using the spatial mode superposition method. 
(1) The relative displacement between track and beam is neglected, while the elastic deformation of fasteners and rail cushion plate is also neglected.

(2) To analyze the vibration mode of the whole track bridge is necessary. It is required that the vibration modes of the main girder joints are identical with those of the bridge deck tracks, and the values of the vibration modes between the nodes are determined by Lagrange interpolation.

(3) For the solid girder bridge, the deformation of the cross section is neglected. For hollow structures, cross-section deformation can be considered in vibration modal analysis.

Based on the above assumptions, Beam element is used to simulate concrete, steel and steel-concrete structural members, such as beam, tower, pier and cap structure. The shear and torsional stiffness of the bridge can be considered by this element; Link element is used to simulate the tension cable; Mass element is used to simulate second-stage dead load. Boundary Conditions: Vertical support is provided across the longitudinal girders on both sides of piers $\mathrm{P} 1 \sim \mathrm{P} 4$ and $\mathrm{P} 7 \sim \mathrm{P} 10$; elastic connection is adopted between the main girders and the bridge towers; and consolidation is adopted between the piers and the foundations. At the same time, this paper also analyzes the influence of bearing characteristics, taking into account the modeling of bridge bearings and the dynamic coupling effect of bearings, beams and substructures. The finite element model of the bridge is shown in Fig. 3.

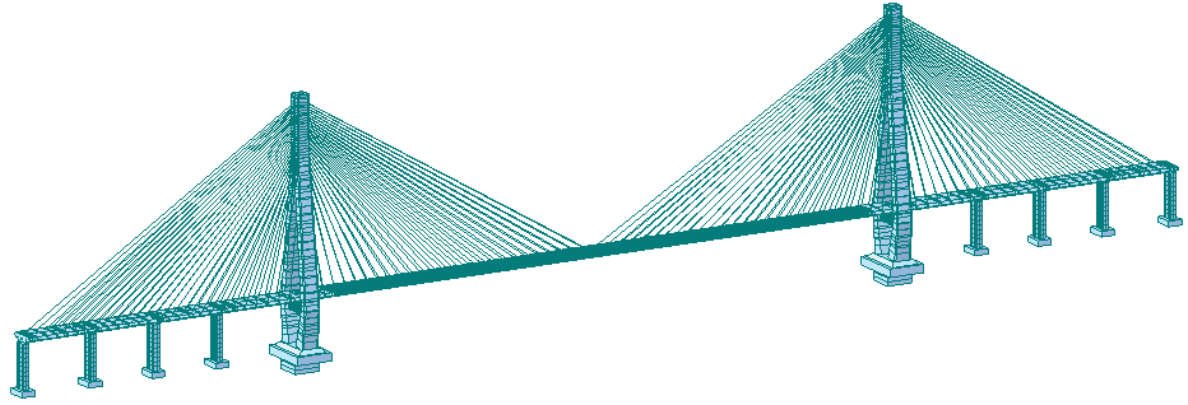

Figure 3 The Finite Element Model of the bridge

\subsection{Vehicle Model}

Railway vehicles are usually multi-degree-of-freedom space vibration systems consisting of components such as car bodies, bogies, wheel sets, springs and dampers. In the analysis of vehicle-bridge coupled vibration, because more attention is paid to the influence of vehicle as a whole on the vibration performance of the bridge, a relatively simplified vehicle model can be adopted, and the following assumptions are usually made [1]:

(1) Regardless of the elastic deformation of the car body, bogie and axle, it is considered that the car body, bogie and wheel set are rigid bodies.

(2) The wheel set and the car body move at the same speed along the line without considering the effect of longitudinal dynamic force.

(3) Wheels are always in contact with rails, that is, wheels cannot be suspended.

(4) The single stage suspension and wheel set alignment are linear.

(5) Damping between all suspension systems of vehicles is calculated according to viscous damping.

(6) The car body is symmetrical about the center of mass.

(7) The car body, bogie and wheels all make small displacement vibration around the basic equilibrium position.

Therefore, the car body and bogie include five degrees of freedom, including sinking, yaw, roll, nod and shake. A single wheel set contains four degrees of freedom, including sinking, yaw, roll and shake, so the whole vehicle model has 31 degrees of freedom. The coordinate system is shown in Fig. 4.

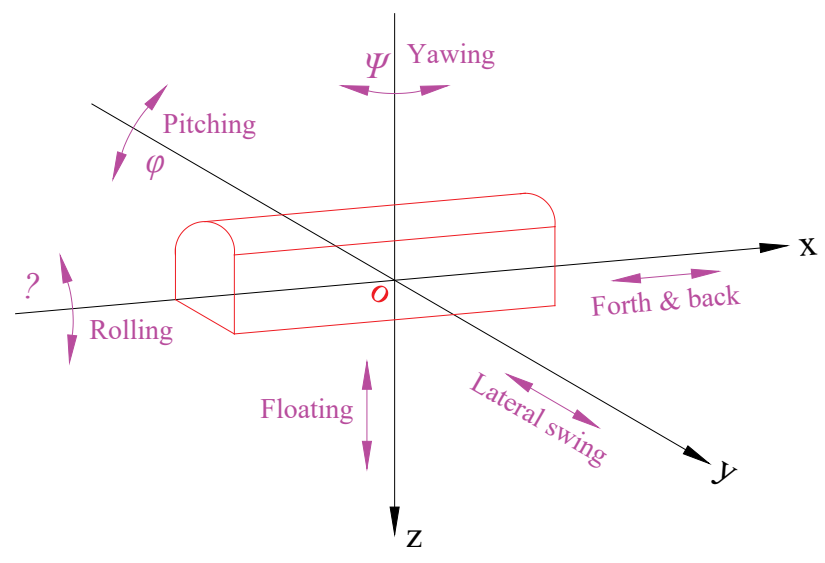

Figure 4 The coordinate system of the vehicle model

\subsection{The Influence of Structural Nonlinearity}

Three aspects mainly cause the structural nonlinearity of Railway cable-stayed bridge: large displacement of structure; displacement caused by axial force and the cable's self-weight buckling. Existing researches [30-32] show that the difference between the internal force and deformation of the cable-stayed bridge is generally less than $10 \%$ without considering the above-mentioned structural nonlinearity factors. For the vehicle-bridge coupling vibration analysis, considering the vibration of vehicle, track and bridge at the same time is a very complex dynamic problem; and the bridge deformation caused by vehicle load is very small; therefore, the influence of large displacement non-linear factors is often ignored in vehiclebridge coupling vibration analysis. For the displacement caused by the axle force, it is simple to consider only the effect of the axle force of the structure under dead load, ignoring the change of the axle force caused by live load; 
for the effect of the cable's self-weight buckling, the elastic modulus can be approximately modified according to the Ernst Eq. (1).

$$
E_{\mathrm{eq}}=\frac{E}{1+\frac{(W \cdot L)^{2} \cdot A \cdot E}{12 \cdot T^{3}}}
$$

where: $E_{\text {eq }}$ represents the equivalent elastic modulus of the cable after considering the effect of droop caused by dead weight; $E$ represents the effective elastic modulus of the steel when the cable's buckling is not taken into account; $L$ represents the projection length of each cable in the horizontal direction; $W$ represents the dead weight per unit length of each stay cable; $A$ represents the cross-sectional area of each stay cable; $T$ represents the tension of each stay cable.

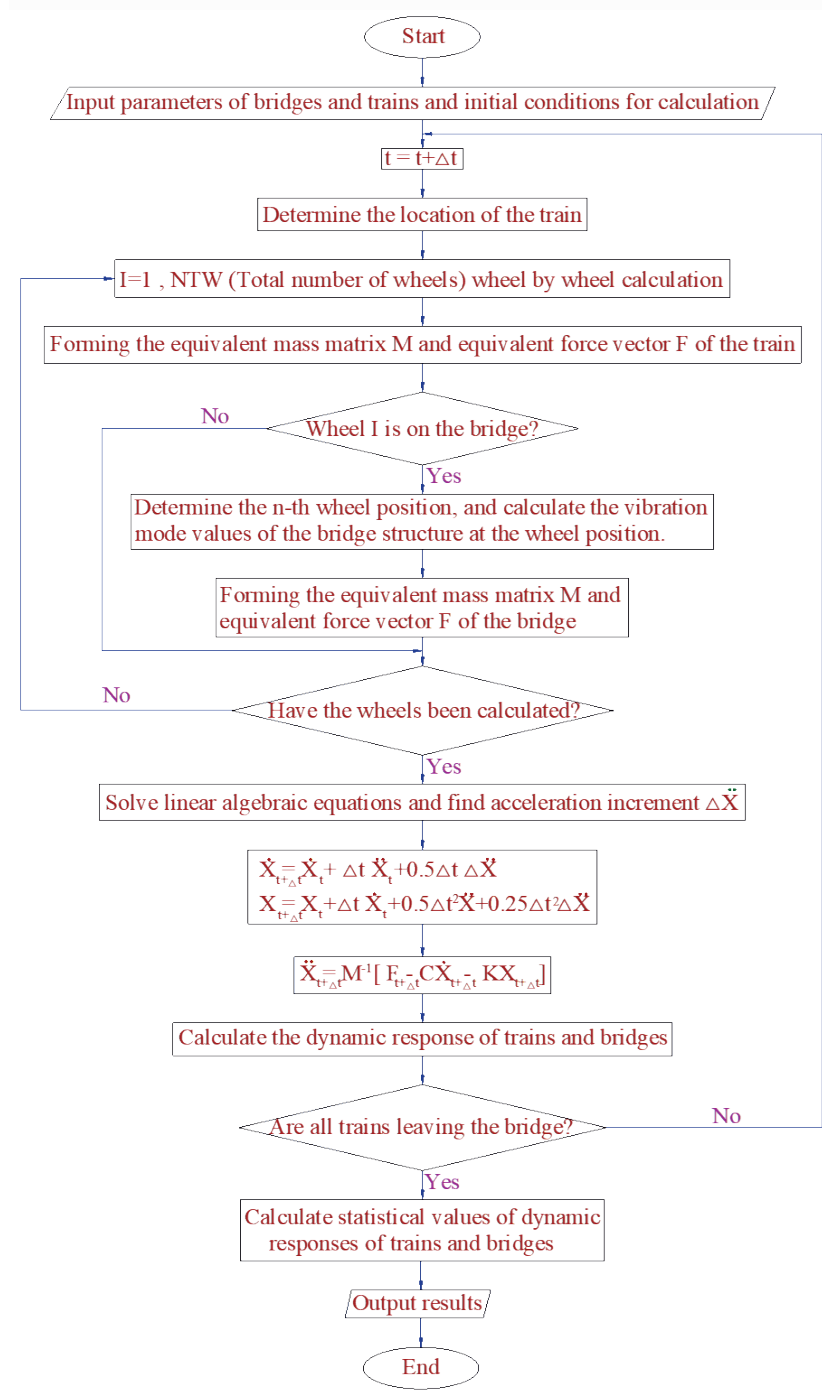

Figure 5 Operation flowchart of self-compiling program

\subsection{Train-Bridge Interaction}

Generally speaking, the analysis methods of vehiclebridge coupling vibration include time-domain method and frequency-domain method. This bridge uses the time domain method to study the vehicle-bridge coupled effect. The vibration differential equations of vehicles and bridges are established respectively, and the two subsystems are coupled by the equilibrium relationship between the displacement coordination conditions at wheel-rail contact and wheel-rail interaction forces, and the group iteration method is adopted to solve the response. The dynamic behavior of the bridge and train is typically governed by the motion equation, which is expressed as follows in matrix form, respectively:

$$
\begin{aligned}
& {\left[\boldsymbol{M}_{\mathrm{b}}\right]\left\{\boldsymbol{X}_{\mathrm{b}}\right\}+\left[\boldsymbol{C}_{\mathrm{b}}\right]\left\{\boldsymbol{X}_{\mathrm{b}}\right\}+\left[\boldsymbol{K}_{\mathrm{b}}\right]\left\{\boldsymbol{X}_{\mathrm{b}}\right\}=\left\{\boldsymbol{F}_{\mathrm{b}}\right\}} \\
& {\left[\boldsymbol{M}_{\mathrm{v}}\right]\left\{\boldsymbol{X}_{\mathrm{v}}\right\}+\left[\boldsymbol{C}_{\mathrm{v}}\right]\left\{\boldsymbol{X}_{\mathrm{v}}\right\}+\left[\boldsymbol{K}_{\mathrm{v}}\right]\left\{\boldsymbol{X}_{\mathrm{v}}\right\}=\left\{\boldsymbol{F}_{\mathrm{v}}\right\}}
\end{aligned}
$$

where $[\boldsymbol{M}],[\boldsymbol{C}],[\boldsymbol{K}]$ are the mass matrix, damping matrix, and stiffness matrix, respectively; $\{\boldsymbol{F}\}$ is the interaction vector applied to the bridge deck as a result of the vibration of the moving train; $\{\boldsymbol{X}\}$ is the displacement vector of the system. The subscript $b$ indicates the bridge and $\mathrm{v}$ indicates the vehicle. The solutions of Eq. (2) and Eq. (3) depend on the interactive force vectors $\left\{\boldsymbol{F}_{\mathrm{b}}\right\}$ and $\left\{\boldsymbol{F}_{\mathrm{v}}\right\}$; that is, the wheel-rail interaction model for the coupled train-bridge dynamic system. The compatibility equations for displacement, whereby the wheel sets have the same motion as the bridge deck in the vertical direction, were used to calculate the wheel-rail interaction. The position of the wheel sets is constantly changing with time, and the results of solving the equation at different times are constantly changing and affecting each other. This paper uses the MATLAB software to compile the vehicle-bridge coupled vibration differential equation, see Fig. 5, and uses Newmark-beta method to analyze and solve it. At the same time, using the finite element analysis software ANSYS as the platform, ANSYS Parametric Design Language (APDL) is compiled to solve the command flow iteratively.

\section{CONTENT AND MEASUREMENT ARRANGEMENT OF DYNAMIC LOAD TEST}

The dynamic load test of main bridge includes pulsation test, driving test and braking test. Pulsating test is used to measure the bridge response caused by natural excitation and obtain the natural modal frequency, mode shape and critical damping ratio of the bridge. The dynamic strain, dynamic deflection, vibration acceleration, derailment coefficient and load reduction rate of the main span and the side span are obtained through driving test and braking test. The single train used in the field driving test and braking test is composed of 2DF4D (locomotive) $+20 \mathrm{C} 70$ (heavy truck) $+20 \mathrm{C} 70$ (empty truck). The test speed includes $5 \mathrm{~km} / \mathrm{h}$ (nominal speed test), 40, 50, 60, 70 and $80 \mathrm{~km} / \mathrm{h}$, and each speed corresponds to the single-line running condition of the train. In the dynamic load test, the mid-span section of steel girder (A-A), the steel-concrete composite section (B-B), the mid-span section of concrete girder (C-C) are selected, as shown in Fig. 1.

\section{DYNAMIC LOAD TEST RESULTS AND ANALYSIS 5.1 Analysis of Natural Vibration Characteristics}

The inherent natural vibration characteristics of bridges can well reflect its dynamic performance, so the natural vibration characteristics of bridge are analyzed in detail before vehicle-bridge coupled vibration analysis. The natural vibration frequency and mode of the bridge are 
obtained by taking into account the influence of the second-stage dead load on the deck system and the pier stiffness, which is shown in Tab. 1. The on-site measured natural vibration frequency of the bridge is carried out by the pulsation method. Through the spectrum analysis of the pulsating waveform, the results are shown in Tab. 1. where the critical damping ratio can be calculated according to the vibration attenuation curve measured by the test and the following formula:

$$
D_{\mathrm{r}}=\frac{1}{2 m \pi} \ln \frac{A_{i}}{A_{i+m}}
$$

In the formula, $D_{r}$ is the damping ratio of the measuring point; $m$ is the number of waveforms measured on the vibration attenuation curve; $A_{i}$ is the amplitude of the $i^{\text {th }}$ waveform measured.

\begin{tabular}{|c|c|c|c|c|c|c|}
\hline No. & $\begin{array}{c}\text { Actual } \\
\text { Frequency / Hz }\end{array}$ & $\begin{array}{c}\text { Calculated } \\
\text { frequency / Hz }\end{array}$ & Error / \% & Vibration mode & $D_{\mathrm{r}}$ \\
\hline 1 & 0,39 & 0,41 & 5,13 & Transverse first-order & \\
\hline 2 & 0,49 & 0,52 & 6,12 & $\begin{array}{c}\text { Vertical } \\
\text { first-order }\end{array}$ & \\
\hline 3 & 0,88 & 0,90 & 2,27 & Longitudinal first-order & 0,09 \\
\hline
\end{tabular}

By comparing the measured results with the calculated ones, it can be seen that the transverse and vertical firstorder bending frequencies and longitudinal first-order drift frequencies of the main bridge are in good agreement, and are slightly lower than the calculated ones. The reason is that the secondary factors are neglected in the calculation of vehicle coupling theory. The first vibration mode of the bridge is the symmetric transverse bending of the main beam, which causes the swing of the cable. The appearance of the transverse mode before the vertical mode indicates that the transverse stiffness is relatively weak compared to vertical stiffness. The second vibration is symmetrical vertical bending with a vibration frequency of $0,49 \mathrm{~Hz}$, which is 1,25 times of the first transverse natural vibration frequency, and this shows again that the vertical stiffness is larger than the transverse stiffness. The measured transverse first-order bending frequency of $0,39 \mathrm{~Hz}$ is higher than the limit of $0,214 \mathrm{~Hz}(f=100 / L=100 / 468=$ $0,214 \mathrm{~Hz}$ ) for simply supported beams in the code [33], which reflects that the transverse stiffness of the bridge is better. By comparing the measured and calculated modes, it can be seen that the two modes are in good agreement, which clearly reflects the first transverse, vertical and longitudinal modes of the structure, and conforms to the basic principles of dynamics, thus verifying the validity of the finite element model.

\subsection{Analysis of Dynamic Strain and Dynamic Coefficient}

In order to illustrate the variation trend of dynamic strain under different sections and different driving speeds, dynamic coefficient was used to characterize it. Dynamic coefficient refers to the ratio of the maximum dynamic effect to the corresponding static effect of the structure or component subjected to dynamic load. The calculation formula is as follows [29]:

$$
1+\mu=\frac{2 w_{d \max }}{w_{d \text { max }}+w_{d \text { min }}}=\frac{2 \varepsilon_{d \text { max }}}{\varepsilon_{d \text { max }}+\varepsilon_{d \min }}
$$

where, $w_{d \max }, \varepsilon_{d \max }$ and $w_{d \min }, \varepsilon_{d \min }$ are respectively the maximum and minimum values of the measured deflection and strain.

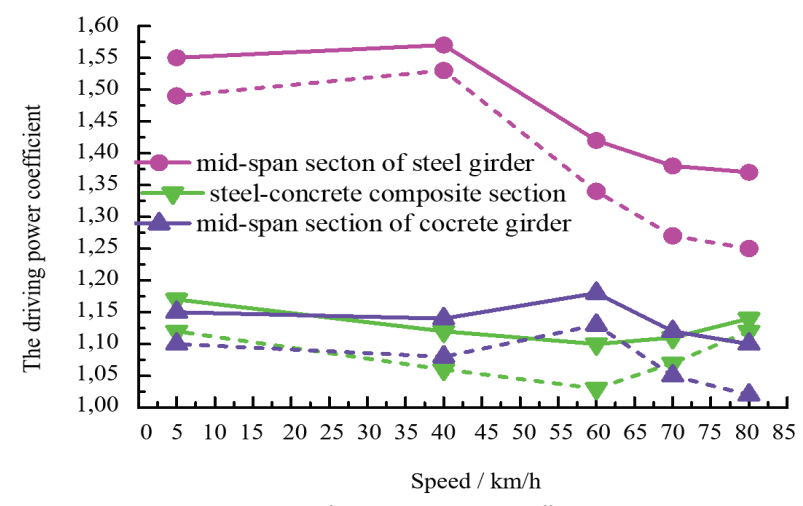

Figure 6 The curve of driving dynamic coefficient with speed

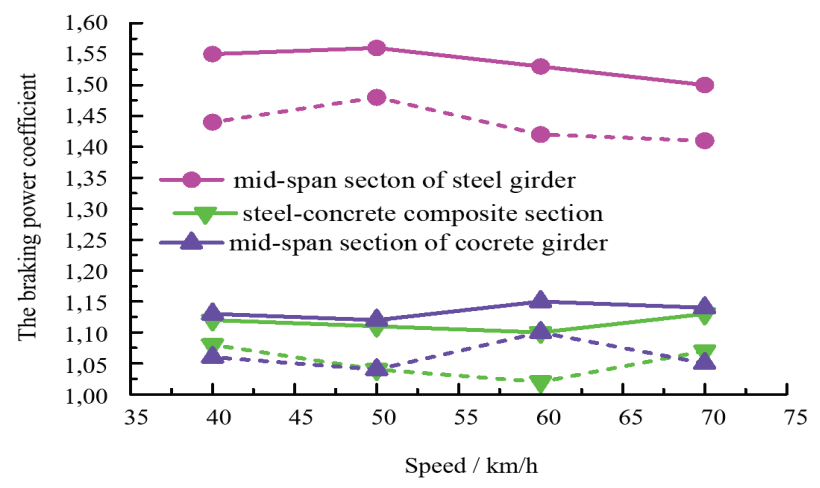

Figure 7 The curve of braking dynamic coefficient with speed

The dynamic coefficients of typical test sections when the test train passes through the bridge at different uniform speeds are shown in Fig. 6 and Fig. 7 (the solid line and 
dotted line represent the measured value and the calculated value, respectively; the following figures also follow this rule), it can be seen that the driving dynamic coefficients on different sections vary with the increase of driving speed. Among them, the driving longitudinal dynamic coefficients of the mid-span section in steel box girder and concrete girder first increase and then decrease with the increase of driving speed, reaching the maximum at 40 $\mathrm{km} / \mathrm{h}$ and $60 \mathrm{~km} / \mathrm{h}$ respectively. The driving longitudinal dynamic coefficients of the steel-concrete composite section decrease first and then increase with the increase of vehicle speed, reaching the minimum value at $60 \mathrm{~km} / \mathrm{h}$. The braking dynamic coefficient of different sections of the main bridge is consistent with the variation trend of the driving braking coefficient, except that the speed varies when the extreme value is reached. The longitudinal dynamic coefficients of the mid-span section in steel box girder and concrete girder reach the maximum at $50 \mathrm{~km} / \mathrm{h}$ and $60 \mathrm{~km} / \mathrm{h}$ respectively, while the steel-concrete composite section reaches the minimum value at $60 \mathrm{~km} / \mathrm{h}$. Therefore, the dynamic effects of train running and braking on the bridge are not consistent in various parts, and it is necessary to put forward the dynamic coefficient values suitable for cable-stayed bridges considering the speed of train.
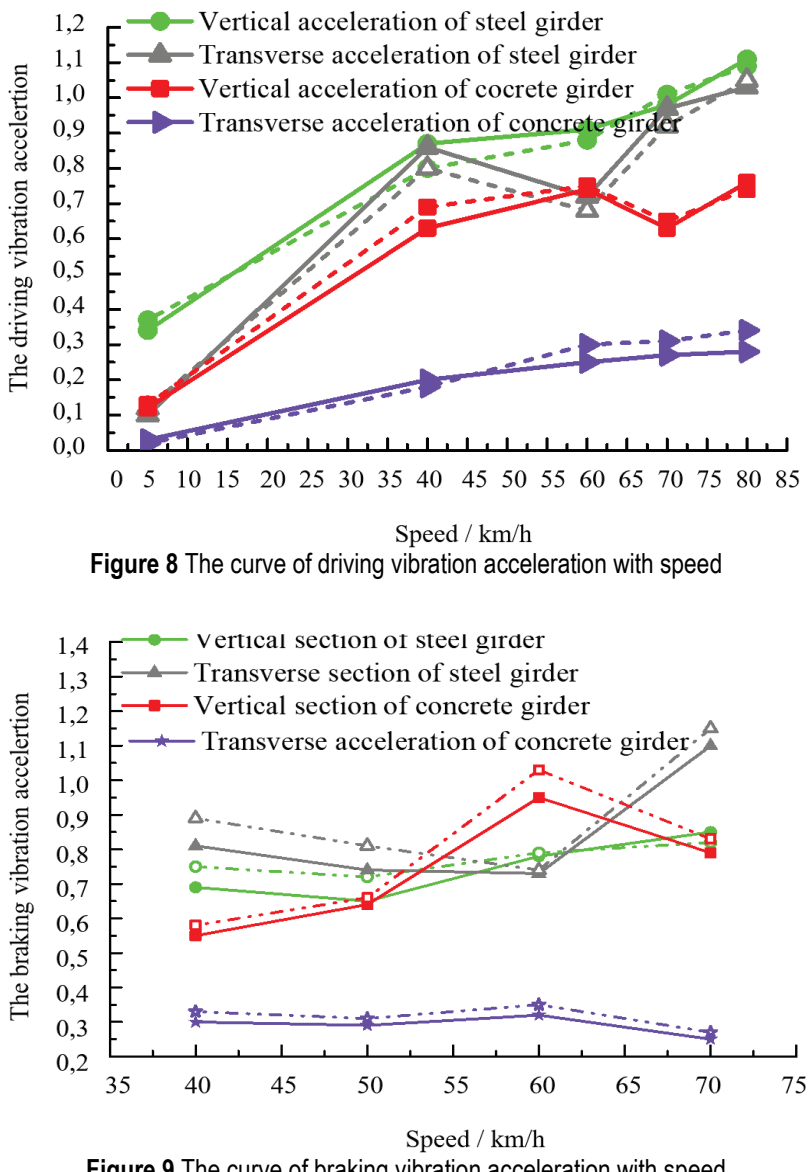

Figure 9 The curve of braking vibration acceleration with speed

\subsection{Dynamic Deflection}

Dynamic deflection is the main index to measure the overall stiffness of the bridge structure. The dynamic impact coefficient of the bridge can be obtained from Eq. (4), so as to evaluate the overall performance and driving condition of the bridge.

Fig. 10 and 11 respectively show the variation curves of dynamic coefficient with vehicle speed under driving and braking at the middle section of the bridge. It can be seen from Fig. 8 and Fig. 9 that the calculated results of vehicle-bridge coupled vibration are in good agreement with the measured results, the errors are within $4,5 \%$, and the calculated values are greater than the measured values. On the whole, the change rules of them are basically the same. The dynamic coefficients of the train running and braking increase first and then decrease with the increase of the running speed. In the one-way driving experiment, the maximum dynamic coefficient measured in the midspan section in steel box girder occurs when the speed is equal to $60 \mathrm{~km} / \mathrm{h}$ and the maximum value is 1,045 ; in the one-way braking experiment, the maximum dynamic coefficient measured in the mid-span section in steel box girder occurs when the speed is equal to $50 \mathrm{~km} / \mathrm{h}$ and the maximum value is 1,058 ; both of them are relatively small, so the dynamic effects of train running and braking on the bridge are not obvious.

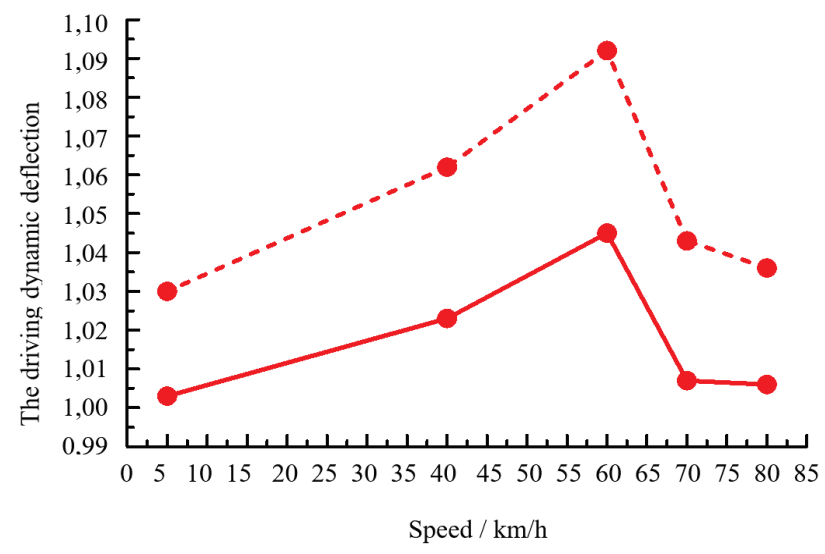

Figure 10 The curve of driving dynamic deflection with speed

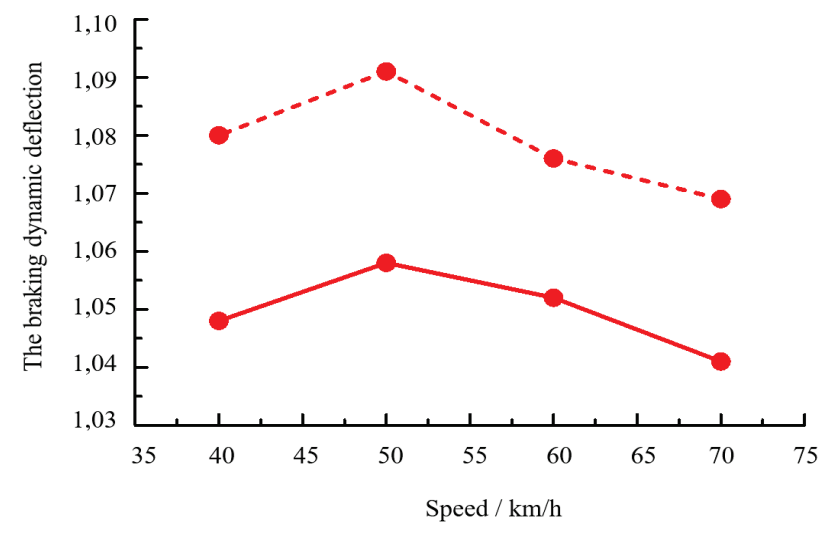

Figure 11 The curve of braking dynamic deflection with speed

From the measured results of dynamic deflection of the mid-span section in steel box girder, it can be seen that the dynamic deflection of the mid-span section in steel box girder increases first and then decreases with the increase of vehicle speed. Under the test condition, the maximum dynamic deflection is $144,028 \mathrm{~mm}$, and the deflection-span ratio is $3,08 \times 10^{-4}$, which is less than the limit value 8,33 $\times 10^{-4}$ required by the verification code [33] for steel plate beams, indicating that the vertical stiffness of the bridge is good. 


\subsection{Acceleration Analysis}

Acceleration is used to represent the impact force in bridge vibration and to reflect the comfort degree during driving. The influence of vehicle speed on the bridge vibration is related to the smoothness of track. Generally, the lower the pavement grade is, the more severe the vibration and the greater the acceleration will be.

Fig. 8 and Fig. 9 show the curves of vibration acceleration with vehicle speed under driving and braking at various typical parts of the main bridge. There are differences between the measured vibration acceleration and the calculated value of vehicle-bridge coupled vibration, which is because the track irregularity used in the calculation is based on the fitting of the six-level spectrum in the United States [29], rather than the measured track irregularity. Generally speaking, the change rules of the two methods are in good agreement, which shows that the vehicle-bridge coupled calculation model is safe and reliable, and can be used to measure the dynamic load test of this bridge.

In one-way driving test, the maximum vertical and transverse accelerations of the mid-span section in steel box girder are $1,1 \mathrm{~m} / \mathrm{s}^{2}$ and $1,07 \mathrm{~m} / \mathrm{s}^{2}$ respectively; the maximum vertical and transverse accelerations of the midspan section in concrete box girder are $0,76 \mathrm{~m} / \mathrm{s}^{2}$ and 0,28 $\mathrm{m} / \mathrm{s}^{2}$ respectively; they are all less than the vertical and lateral acceleration limits of $3,5 \mathrm{~m} / \mathrm{s}^{2}$ and $1,4 \mathrm{~m} / \mathrm{s}^{2}$ in the code [33], indicating that the bridge has good vertical and lateral dynamic performance. According to the relevant specifications [34], the lateral acceleration of the vehicle is less than $5,0 \mathrm{~m} / \mathrm{s}^{2}$, and the vertical acceleration is less than $7,0 \mathrm{~m} / \mathrm{s}^{2}$. Combined with the comprehensive evaluation of the stability index, the level of the train's stability is "excellent", which indicates that the train has good stability when running on the bridge.

At the same time, it is found that except for a few value points, the vibration acceleration generally increases with the increase of driving speed. By comparing the responses of the bridge structure caused by train running and braking, it can be seen that the acceleration of each section is smaller under braking condition, indicating that train braking has little influence on the vibration acceleration of the bridge. Meanwhile, excluding individual extreme points, the vibration acceleration does not change much with the increase of running speed during train braking.

\subsection{Analysis of Derailment Coefficient and Load Reduction Rate}

Wheel derailment may occur under the most disadvantageous combination of line conditions, operation conditions, vehicle structural parameters and loading conditions. The "derailment coefficient" is used to evaluate the stability of wheel derailment prevention. The calculation formula is given by Nadal [29].

$$
\frac{Q}{P}=\frac{\tan \alpha-\mu}{1+\mu \cdot \tan \alpha}
$$

where, $Q$ represents the lateral force acting on the wheel; $P$ represents the vertical force acting on the wheel; $\mu$ represents the friction coefficient at the rim; $\alpha$ represents the maximum rim contact angle. The greater the critical derailment coefficient is, the greater the risk of derailment is.

For the safety of wheel derailment, it is not enough to study derailment coefficient only because when the train is running at high speed, the wheels move up and down in the process of vibration, and the wheel weight between wheel pairs will increase or decrease. If the lateral force corresponding to the side with smaller wheel weight is also small, the greater the influence of lateral force measurement error will be. At this time, the derailment coefficient obtained cannot well reflect the safety of wheel derailment. In addition, when the wheel weight on one side is reduced, the wheel weight on the other side will increase, and a small change in attack angle may produce a large lateral force, which increases the risk of derailment. Therefore, it is necessary to limit the load reduction of wheel weight, and the load reduction rate of wheel weight $\Delta P / P$ must be defined. The formula is as follows [29]:

$\frac{\Delta P}{P}=\frac{P_{2}-P_{1}}{P_{2}+P_{1}}$

where, $\Delta P$ is the wheel weight reduction load of the wheel on the load reduction side, and $P$ is the average static wheel weight of the wheel on the load reduction and load increase side.

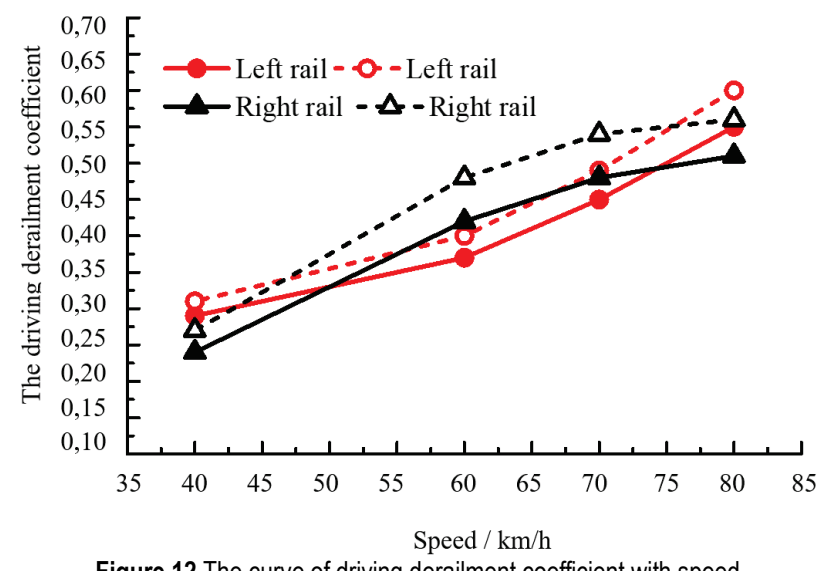

Figure 12 The curve of driving derailment coefficient with speed

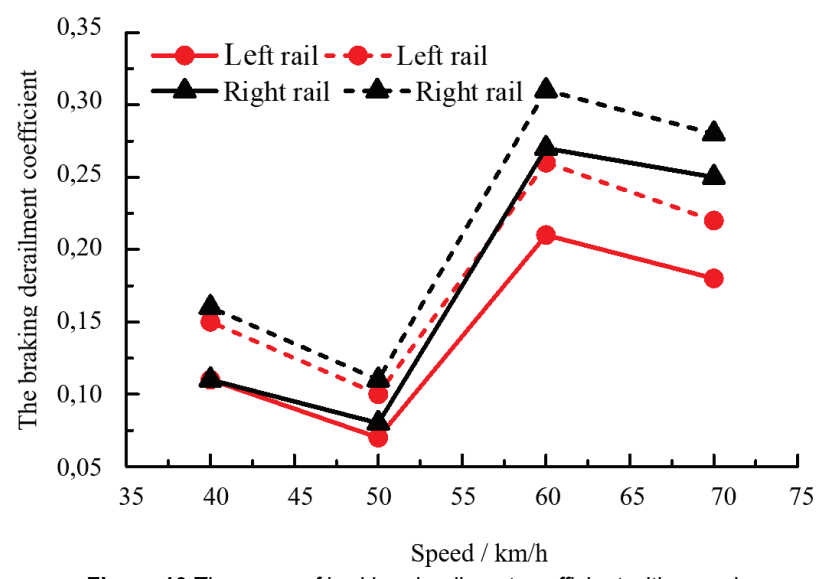

Figure 13 The curve of braking derailment coefficient with speed

Fig. 12 and Fig. 13 respectively show the variation curves of measured and calculated derailment coefficients 
with vehicle speed under driving and braking of the bridge. It can be seen that the measured derailment coefficient is different from the calculated value of vehicle-bridge coupled vibration. The main reason is that the track irregularity of the actual bridge is different from that of vehicle-bridge coupled calculation. In the one-way driving (braking) test, the maximum derailment coefficients of the left and right rails are $0,55(0,21)$ and $0,51(0,27)$ respectively, which are not greater than the limit value 0.8 specified in the code [34].

According to the code [35], the measured maximum derailment coefficient of the bridge is 0,55 . Combined with the comprehensive evaluation of safety indexes, the safety grade of the train is "excellent", indicating that the train has good safety when running on the bridge. Moreover, it is found that with the increase of train speed, the variation trends of the derailment coefficients of driving and braking are different and need to be studied separately.

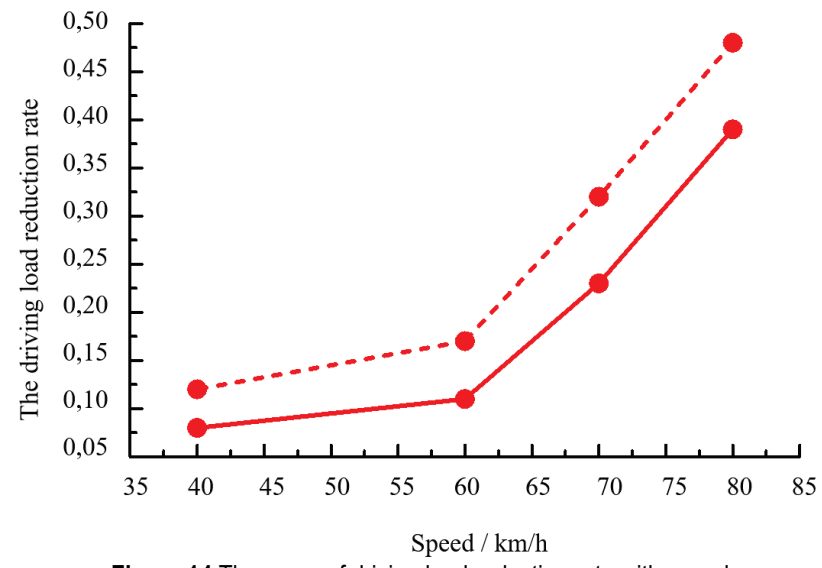

Figure 14 The curve of driving load reduction rate with speed

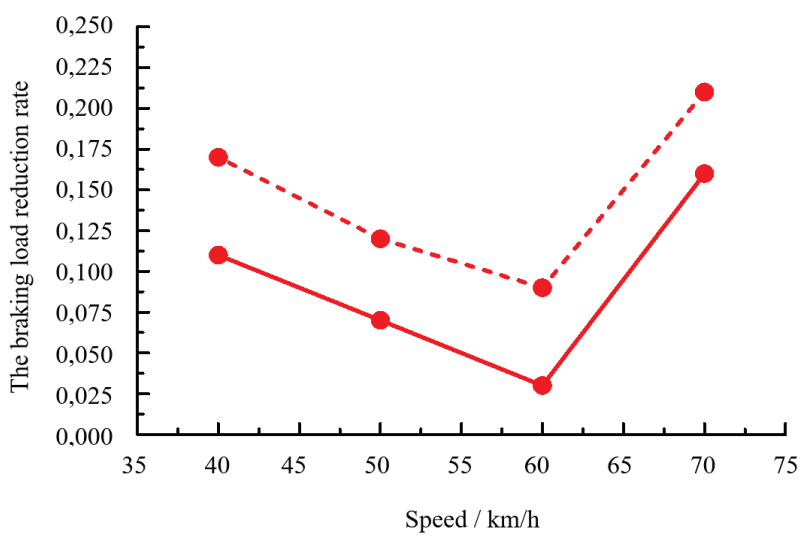

Figure 15 The curve of braking load reduction rate with speed

Fig. 14 and Fig. 15 show the variation curves of measured and calculated values of load reduction rate with vehicle speed under driving and braking of the bridge. It can be seen that the measured load reduction rate of the cross section is different from the calculated value of vehicle-bridge coupled vibration, but on the whole, the variation law of them is in good agreement, and the calculated value is larger than the measured value. In the one-way driving (braking) test, the maximum load reduction rates are $0,39(0,16)$ respectively, which are not more than the limit value of 0,60 specified in the code [34], indicating that the train has good safety and stability when running on the bridge. At the same time, it is found that the train derailment coefficient increases with the increase of the speed, and the brake derailment coefficient first decreases and then increases with the increase of the speed, and reaches a minimum at $60 \mathrm{~km} / \mathrm{h}$.

\section{CONCLUSION}

Based on the above investigations, the following conclusions can be drawn:

(1) The analysis of vehicle-bridge coupling vibration shows that the dynamic response values, such as derailment coefficient, wheel load reduction rate, wheel axle transverse force and vibration acceleration, are less than the code [33-35] when the train passes through the bridge, and the train runs on the bridge with good safety and stability.

(2) The measured transverse fundamental frequency of Yongjiang Bridge is $0,39 \mathrm{~Hz}$, and the calculated value is basically in accordance with the measured value. The measured vertical first-order frequency of $0,49 \mathrm{~Hz}$ is slightly lower than the frequency limit of $0,62 \mathrm{~Hz}(f=23,58$ $\times 468^{-0.592}=0,62 \mathrm{~Hz}$ ) for simple supported beams with the same span in the Interim regulations on the design of new passenger and freight trains with a speed of $200 \mathrm{~km} / \mathrm{h}$. Practice shows that the bridge is in good condition. Therefore, it is inappropriate to limit the natural vibration frequency of cable-stayed bridges with the same frequency limit as simple supported beams, and a limit applicable to the natural vibration frequency of cable-stayed bridges needs to be proposed. The longitudinal and transverse stiffness of the bridge meet the specification requirements.

(3) The dynamic coefficients of the main span, the steel-concrete composite section and the side span of Yongjiang Bridge are 1,04 - 1,06; 1,11 - 1,13 and 1,101,12 respectively, which are slightly larger than the dynamic coefficients of 1,05 calculated according to the Interim regulations on the design of new passenger and freight trains with a speed of $200 \mathrm{~km} / \mathrm{h}$. Therefore, it is urgent to put forward the dynamic coefficients suitable for cable-stayed bridges.

(4) Under the action of test trains, the maximum lateral and vertical accelerations of Yongjiang Bridge are $1,03 \mathrm{~m} / \mathrm{s}^{2}$ and $1,11 \mathrm{~m} / \mathrm{s}^{2}$, respectively, which are in good agreement with the calculated results of the program 1,05 $\mathrm{m} / \mathrm{s}^{2}$ and $1,09 \mathrm{~m} / \mathrm{s}^{2}$, and are all less than the lateral and vertical acceleration limits of $1,4 \mathrm{~m} / \mathrm{s}^{2}$ and $3,5 \mathrm{~m} / \mathrm{s}^{2}$ in the Code for Rating Existing Railway Bridges, indicating that the bridge has good lateral and vertical dynamic performance.

(5) The maximum lateral amplitude and dynamic deflection of the control section of the bridge are all less than the prescribed limit value of the simple supported beam with the same span under various speed driving and braking test conditions, indicating that the bridge has good lateral and vertical stiffness.

(6) The measured maximum derailment coefficient and load reduction rate are 0,55 and 0,39 , respectively, and are in good agreement with the calculated results of the program, 0,60 and 0,48. They are not greater than the limits of 0,8 and 0,6 stipulated in the Interim regulations on the design of new passenger and freight trains with a speed of $200 \mathrm{~km} / \mathrm{h}$. The safety of trains belongs to the "excellent" grade. 


\section{REFERENCES}

[1] Xia, H. \& Zhang, N. Dynamic Interaction of Vehicles and structures. Beijing: Science Press.

[2] Frýba, L. (1976). Non-stationary response of a beam to a moving random force. $J$ Sound Vib, 46, 323-338. https://doi.org/10.1016/0022-460X(76)90857-9

[3] Shan, D. \& Li, Q. (2005). Coupled Vibration Analysis of XStyle Arch Bridge and Vehicles. Journal of Southwest Jiaotong University, 2005(01), 53-57.

[4] Gładysz, M. \& Sniady, P. (2009). Spectral density of the bridge beam response with uncertain parameters under a random train of moving forces. Arch Civ Mech Eng, 9, 3147. https://doi.org/10.1016/S1644-9665(12)60216-7

[5] Wei, X., Li, X., Li, J., et al. (2009). Dynamic loading test of continuous rigid-frame railway bridge. Journal of vibration and shock, 2009(11), 118-121.

[6] Cui, S., Shan, D., \& Zhu, B. (2011). Simulation of VehicleBridge Coupled Vibration for Yujiang River Bridge on Nanning-Guangzhou High-Speed Railway. Journal of Southwest Jiaotong University, 2011(03), 385-390.

[7] Zhai, W. \& Wang, S. (2012). Influence of Bridge Structure Stiffness on the Dynamic Performance of High-Speed TrainTrack-Bridge Coupled System. Chia Railway Science, 2012(01), 19-26.

[8] Zeng, Q., Zhou, Z., He, D., Wen, Y. et al. (2012). Study on Stability of Lateral Vibration of Train-track(bridge) System. Journal of the China Railway Society, 2012(05), 86-90.

[9] Rocha, J. M, Henriques, A. A, \& Calçada, R. (2016). Probabilistic assessment of the train running safety on a short-span high-speed railway bridge. Struct Infrastruct Eng, 12, 78-92. https://doi.org/10.1080/15732479.2014.995106

[10] Gou, H., Shi, X., Zhou, W., et al. (2017). Study on the Coupled Train-bridge Vibration and Dynamic Characteristics of Long Span T-Shaped Rigid Frame Railway Bridge. Journal of Southwest Jiaotong University, $1-6$.

[11] Li, X., Wang, Y., \& Qiang, S. (1999). Spatial Vibration Analysis of Long Span Continuous Arch-Truss Composite Steel Bridge. Journal of Vibration and Shock, 18(4):35-39

[12] Li, X. \& Qiang, S. (2003). Dynamic Analysis of VehicleBridge of Cable-Stayed Bridge. Journal of Vibration and Shock, 22(1), 6-13

[13] Wu, D., Wang, X., \& Xiang, H. (2003). The Bridge-vehicle Dynamics Characteristic of Nelson Arch Bridge in High Speed Railway. Journal of the China Railway Society, 25(3).

[14] Luo, H. \& Guo, X (2008). Vehicle-bridge Coupled Vibration Analysis of Basket-lifting Arch Bridge. Journal of Vibration and Shock, 27(2), 147-149, 165.

[15] Zhang, H., Zhang, Z., Xie, X., \& Gong, R. (2008). Theoretical Study on The Impact Factor of Crescent-shaped Multi-rib Concrete Filled Steeltube Truss Arch Bridges. Engineering Mechanics, 25(7), 118-123. https://doi.org/10.3901/JME.2008.07.118

[16] Li, B. (2008). Study on Vehicle-Bridge Coupled Vibration of Concrete Filled Steel Tubular Arch Bridge of High-Speed Railway under Earthquake. Master Thesis of Central South University.

[17] Cui, S. \& Zhu, B. (2009). Coupling Vibration Simulation ofLong-Span Continuous Beam Bridge on Passenger Dedicated Railway. Journal of Southwest Jiaotong University, 44(1), 66-71.

[18] Guo, Z. (2010). Research on Vehicle-Bridge Coupled Vibration of Railway Special-Shaped Arch Bridge. Master's Thesis of Central South University.

[19] Li, Y., Chen, Y., \& Huang, X. (2010). Impact Effect Study on Irregular Concrete Filled Steel Tube Arch Bridge under Moving Vehicles. Journal of Harbin Institute of Technology, 42(1), 109-114.

[20] Zhang, M. (2012). Analysis of Train-Bridge Coupled
Vibration of Long Span Railway Steel Truss Arch Bridge. Bridge Construction, 40(6), 14-19.

[21] Wang, Y. (2008). Vehicle-bridge coupled dynamical numerical analysis for long span self-anchored suspension bridge. Master's Thesis of Chang'an University.

[22] Hu, X. (2010). Study on vehicle-bridge interaction of highway continuous rigid frame bridge with high piers and. Journal of Southwest Jiaotong University.

[23] Kang, J., Yuan, M., \& Wang, T. (2013). Parametric study of dynamic characteristics of self-anchored suspension bridge under completion state. Bridge Construction, 2013(06), 6470.

[24] Yin, B., Miao, Y., \& Guo, X. (2013). The vehicle-bridge coupling dynamic analysis of cable-stayed and continuous rigid-frame composite beam bridge. Journal of Railway Science and Engineering, 2013(02), 11-17.

[25] Tao, T., Wang, H., Hu, S., \& Zhao, X. (2018). Dynamic Performance of Typical Steel Truss-Railway Bridges under the Action of Moving Trains. Journal of Performance of Constructed Facilities, (08)

[26] Kim, S. I., Lee, J., \& Kim, S. (2011). Dynamic behavior comparison of steel-Composite and concrete high speed railway bridges. International Journal of Steel Structures, (12), 445-455. https://doi.org/10.1007/s13296-011-4005-8

[27] Gou, H., Shi, X., Zhou, W., Cui, K., \& Pu, Q. (2018). Dynamic performance of continuous railway bridges: Numerical analyses and field tests. Proceedings of the Institution of Mechanical Engineers, (03), 936-955. https://doi.org/10.1177/0954409717702019

[28] Liu, P., Yao, J., Yin, J., Dong, Z., Meng, X., Yang, Y., \& Tumu, G. X. (2013). Experimental study on dynamic behavior of $200 \sim 250 \mathrm{~km} / \mathrm{h}$ high-speed railway bridges. China Civil Engineering Journal, (03), 96-102.

[29] Zhai, W. (2007). Vehicle-track coupling dynamics. $3^{\text {rd }}$ ed. Beijing: Science Press.

[30] Yan, G. (1996). Modern Cable - Stayed Bridge. Chengdu: Southwest Jiaotong University Press.

[31] Xu, K. \& Wei, D. (2008). Geometrically Nonlinear Static Analysis of Long Span Cable - Stayed Bridge. Earthquake Resistance and Reinforcement of Engineering, 30(3), 64-68.

[32] Pan, J., Wu, L., \& Gao, L. (1993). Study on Live Load Nonlinearity of Cable-Stayed Bridge. Journal of Civil Engineering, 26(1), 31-36.

[33] Ministry of Railways of the People's Republic of China. Code for Rating Existing Railway Bridges. Beijing: China railway press, 2004

[34] Ministry of Railways of the People's Republic of China. Interim regulations on the design of new passenger and freight trains with a speed of $200 \mathrm{~km} / \mathrm{h}$. Beijing: China railway press, 2005.

[35]National Standards Bureau of the People's Republic of China. GA5599-85 Code for Dynamic Performance Assessment and Test Appraisal of Railway Vehicles. Beijing: China Standards Press, 1986.

\section{Contact information:}

Yadong YAO

Inner Mongolia University,

Hohhot 010020, China

\section{Baishun XU}

(Corresponding author)

Inner Mongolia University,

Hohhot 010020, China

Email: yaoyadong_imu@163.com

\section{Yan WANG}

Inner Mongolia University,

Hohhot 010020, China 